\title{
Epidemiological characterization of resistance and PCR typing of Shigella flexneri and Shigella sonnei strains isolated from bacillary dysentery cases in Southeast Brazil
}

\footnotetext{
M.P.A. Penatti ${ }^{1}$,

L.M. Hollanda ${ }^{1}$, G. Nakazato ${ }^{1}$,

T.A. Campos ${ }^{1}$, M. Lancellotti ${ }^{1}$,

M. Angellini ${ }^{1}$, M. Brocchi ${ }^{1}$,

M.M.M. Rocha ${ }^{2}$

and W. Dias da Silveira ${ }^{1}$
}

\author{
${ }^{1}$ Departamento de Microbiologia e Imunologia, Instituto de Biologia, \\ Universidade Estadual de Campinas, Campinas, SP, Brasil \\ ${ }^{2}$ Instituto Adolfo Lutz, São Paulo, SP, Brasil
}

\section{Correspondence \\ W. Dias da Silveira \\ Departamento de Microbiologia e \\ Imunologia \\ Instituto de Biologia, UNICAMP \\ Caixa Postal 6109 \\ 13081-970 Campinas, SP \\ Brasil \\ Fax: $+55-19-3788-6276$ \\ E-mail: wds@unicamp.br}

Research supported by FAPESP (Nos. 03/08407-0 and 05/60928-0) and CNPq (No. 150800/2005-3).

Received March 23, 2006 Accepted November 24, 2006

\begin{abstract}
Shigella spp are Gram-negative, anaerobic facultative, non-motile, and non-sporulated bacilli of the Enterobacteriaceae family responsible for "Shigellosis" or bacillary dysentery, an important cause of worldwide morbidity and mortality. However, despite this, there are very few epidemiological studies about this bacterium in Brazil. We studied the antibiotic resistance profiles and the clonal structure of 60 Shigella strains ( 30 S. flexneri and 30 S. sonnei) isolated from shigellosis cases in different cities within the metropolitan area of Campinas, State of São Paulo, Brazil. We used the following well-characterized molecular techniques: enterobacterial repetitive intergenic consensus, repetitive extragenic palindromic, and double-repetitive element-polymerase chain reaction to characterize the bacteria. Also, the antibiotic resistance of the strains was determined by the diffusion disk method. Many strains of S. flexneri and S. sonnei were found to be multiresistant. S. flexneri strains were resistant to ampicillin in $83.3 \%$ of cases, chloramphenicol in $70.0 \%$, streptomycin in $86.7 \%$, sulfamethoxazole in $80.0 \%$, and tetracycline in $80.0 \%$, while a smaller number of strains were resistant to cephalothin (3.3\%) and sulfazotrim (10.0\%). S. sonnei strains were mainly resistant to sulfamethoxazole (100.0\%) and tetracycline (96.7\%) and, to a lesser extent, to ampicillin (6.7\%) and streptomycin $(26.7 \%)$. Polymerase chain reaction-based typing supported the existence of specific clones responsible for the shigellosis cases in the different cities and there was evidence of transmission between cities. This clonal structure would probably be the result of selection for virulence and resistance phenotypes. These data indicate that the human sanitary conditions of the cities investigated should be improved.
\end{abstract}

Key words

- Shigella flexneri

- Shigella sonnei

- Antimicrobial resistance

- Enterobacterial repetitive intergenic consensuspolymerase chain reaction

- Repetitive extragenic palindromic-polymerase chain reaction

- Double-repetitive element-polymerase chain reaction 


\section{Introduction}

Shigella spp are Gram-negative, facultative anaerobic, non-motile, and non-sporulated bacilli belonging to the Enterobacteriaceae family. Additionally, they are cytochrome-oxidase negative, an important feature that differentiates Enterobacteriaceae bacilli from other fermentative and non-fermentative bacilli. They are also able to ferment glucose (1), reduce nitrates to nitrites, and produce acids from carbohydrates. However, they are unable to produce $\mathrm{H}_{2} \mathrm{~S}$, urease, desaminase, or lysine decarboxylase (2).

Shigella spp are divided into four groups (or species), namely Shigella flexneri, S. sonnei, S. boydii, and S. dysenteriae. They are responsible for shigellosis or bacillary dysentery, a disease that causes high fever, neurological disturbances, and mucus-pyohemorrhagic dysentery (3). These bacteria are responsible for morbidity and mortality in high risk populations such as children under five years of age, senior citizens, toddlers in day-care centers, patients in custodial institutions, homosexual men, and those affected by war and famine (4). Shigellosis is characterized by destruction of the colonic epithelium due to the inflammatory response induced upon bacterial invasion of the mucosa (5). The worldwide burden of this disease has been estimated to be 150 million cases, with 1 million deaths per year in the developing world (5).

Virulent Shigella species are characterized by the presence of a virulence plasmid of $\approx 220 \mathrm{~kb}$ and by the ability to invade the epithelial cells of the intestinal mucosa, with further dissemination to other cells. Bacterial entry is a consequence of bacterial factors that induce internalization of Shigella by the host cells (5). The invasion process is complex and involves three chromosomal and five plasmid loci (3). The virulence plasmid related to the invasion process was first described in S. flexneri strains (6), and was later found in other serogroups of Shigella, namely $S$. dysenteriae, $S$. boydii, as well as enteroinvasive Escherichia coli (7).

Although genomic analyses have demonstrated that there are no different species among the shighellas (8-11), in the present study for consistency we will use the traditional classification scheme for the genus. Differentiation of Shigella isolates is classically based on serotyping and biochemical assays. However, molecular techniques such as multilocus enzy;.me electrophoresis (12), restriction of amplified O-antigen gene cluster loci (9), pulsed field gel electrophoresis (PFGE), polymerase chain reaction (PCR) $(13,14)$, DNA hybridization (15-17), ribotyping (8), and multilocus enzyme electrophoresis- $m d h$ gene sequencing $(18,19)$, or even a combination of these techniques (20, 21) have also been used.

To our knowledge, only two reports regarding the epidemiology of shigellosis in Brazil have been published to date $(22,23)$. The first describes the resistance profile of strains, while the second uses plasmid, PFGE, and antibiotic resistance profiles to demonstrate the persistence of certain PFGE patterns in the populations studied, as well as the presence of only three plasmid profiles in the strains. A third study (24), which does not involve Shigella strains only, has contributed significantly to the epidemiology of this genus because the authors described relationships among strains on the basis of the DNA sequencing of specific chromosomal and plasmid loci.

The present study was carried out to determine the genomic variability of 60 strains of Shigella spp (30 S. flexneri and $30 \mathrm{~S}$. sonnei strains) isolated from different cases in the Southeast region of Brazil and belonging to the bacterial collection of the Adolfo Lutz Institute (the reference Institute in the State of São Paulo). Additionally, the possible origin and transmission of strains among cities located in the metropolitan area of Campinas, State of São Paulo, Brazil, were investigated. A combination of the entero- 
bacterial repetitive intergenic consensusPCR (ERIC-PCR) (25), repetitive extragenic palindromic-PCR (REP-PCR) (25), and double-repetitive element-PCR (DRE-PCR) (26) techniques was used to characterize the strains. The relationship of these results with antibiotic resistance and plasmid profiles was determined in order to determine the possible origin of the cases.

\section{Material and Methods}

\section{Bacterial strains}

The 30 S. flexneri and 30 S. sonnei strains analyzed in this study were provided by the Adolfo Lutz Institute, São Paulo, SP, Brazil. All available epidemiological data such as patient age, date and city of isolation are described in Table 1. Patient ages below 1 year are reported in months.

\section{Determination of antibiotic resistance}

Ampicillin, cephalothin, chloramphenicol, streptomycin, trimethoprim-sulfamethoxazole, sulfamethoxazole, and tetracycline were used to determine the resistance of all Shigella strains studied by the diffusion disk method according to the Manual of the Clinical and Laboratory Standards Institute (https:/ /www.anvisa.gov.br/servicosaude/manuais/ clsi.asp).

\section{Extraction of genomic and plasmid DNA}

Bacterial genomic DNA was extracted as described by Ausubel et al. (27). DNA integrity was determined by electrophoresis on $0.7 \%$ agarose gel. Plasmid DNA was extracted by the alkaline lysis method and separated by electrophoresis on agarose gels as described by Sambrook et al. (28).

\section{Polymerase chain reaction}

Genomic DNA (20-40 ng), extracted as described by Ausubel et al. (27) and resuspended in sterile deionized water, was used to perform ERIC-PCR (25), REP-PCR (25), and DRE-PCR (26). The following primers were used: ERIC-PCR (ERIC-1R 5'ATG TAAGCTCCTGGGGATTCAC3'); (ERIC2 5'AAGTAAGTGACTGGGGTGAGC G3'); REP-PCR (REP1R 5'IIIICGICGI CATCIGGC3'), (REP2 5'ICGICITATCIG GCCTAC3'); DRE-PCR (PNTB1 5'CCG TTGCCGTACAGCTG3'), (PNTB2 5'CCT AGCCGAACCCTTTG3') (Ris1 5'GGC TGAGGTCTCAGATCAG3'), (Ris2 5'ACC CCATCCTTTCCAAGAAC3') under the PCR conditions described previously $(25,26)$. PCR-amplified DNA fragments were separated by electrophoresis on agarose gel as described by Sambrook et al. (28).

\section{Polymerase chain reaction fingerprint analyses}

The PCR fingerprints of amplified DNA fragments obtained by agarose gel electrophoresis were recorded. The presence of a given band was coded as 1 , and the absence of a given band was coded as 0 in a data matrix. The matrix was analyzed with the POPGENE software, version 1.31 (29), which employs the unweighted pair group method using arithmetic averages. Dendrograms of similarity between the isolates of each Shigella species were constructed.

\section{Results}

We determined the molecular epidemiology of Shigella spp strains (30 S. flexneri and $30 \mathrm{~S}$. sonnei) isolated from shigellosis cases that occurred in different cities in the metropolitan area of Campinas city, State of São Paulo, Southeast Brazil. Each strain was analyzed using specific primer pairs in three different PCR procedures and antibiotic resistance and plasmid profiles were also determined.

Patient age was known in 29 of the 30 
cases reported to be caused by $S$. flexneri and in 22 of the 30 cases reported to be caused by $S$. sonnei (Table 1). S. flexneri strains were detected in $60 \%$ of the patients under 6 years of age and in $36.6 \%$ of the patients over 5 years of age. Isolates from patients older than 60 years represented only $3.3 \%(\mathrm{~N}=1)$ of the cases. Regarding S. sonnei, the cases occurred in 68.8 and $36.3 \%$ of the patients under 6 years of age and over 5 years of age, respectively. There was only one case $(4.5 \%)$ involving a patient older than 60 years (an 87 -year-old patient) and another case involving a 42-year-old patient.

Most of the S. flexneri strains demon- strated multiple drug resistance profiles, with $90 \%$ of them being resistant to at least 3 drugs (Table 1, Figure 1). Of these, 16.7\% were resistant to $3,20 \%$ were resistant to 4 , $50 \%$ were resistant to 5 , and $3.3 \%$ were resistant to 6 antimicrobial agents. Only 1 strain $(3.3 \%)$ was resistant to only one antimicrobial agent and two strains $(6.6 \%)$ were resistant to two different antimicrobial agents (Table 1). The resistance profiles indicated that most of the strains either isolated in the same city or isolated on close dates exhibited a very similar resistance pattern (Table 1); however, there were exceptions, as can be seen for strains Sf3, Sf7,

Table 1. Shigella flexneri and Shigella sonnei strains isolated from cases of shigellosis from the region of the city of Campinas, State of São Paulo.

\begin{tabular}{|c|c|c|c|c|c|c|c|c|c|}
\hline $\begin{array}{l}\text { S. flexneri } \\
\text { strains }\end{array}$ & $\begin{array}{l}\text { Isolation } \\
\text { date }\end{array}$ & City & Age & $\begin{array}{l}\text { Antibiotic } \\
\text { resistance }\end{array}$ & $\begin{array}{l}\text { S. sonnei } \\
\text { strains }\end{array}$ & $\begin{array}{l}\text { Isolation } \\
\text { date }\end{array}$ & City & Age & $\begin{array}{l}\text { Antibiotic } \\
\text { resistance }\end{array}$ \\
\hline Sf1A & $11 / 02 / 87$ & SJBV & 44 years & AP, ET, SUT & Ss1 & $02 / 14 / 97$ & MG & 23 years & ET, SUT, TT \\
\hline Sf1B & $12 / 02 / 87$ & SJBV & 12 years & AP, ET, SUT & Ss2 & $05 / 14 / 97$ & $\mathrm{BP}$ & 15 years & AP, ET, SUT \\
\hline Sf2 & $10 / 03 / 89$ & C & 2 years & CO, ET, SUT, TT & Ss3 & $10 / 15 / 98$ & $\mathrm{~L}$ & 11 years & ET, SUT, TT \\
\hline Sf3 & $04 / 23 / 90$ & $J$ & 35 years & ET, SUT & Ss4 & $06 / 24 / 99$ & C & 10 years & SUT, TT \\
\hline Sf 4 & $11 / 24 / 97$ & $\mathrm{C}$ & 8 months & $\mathrm{AP}, \mathrm{CO}, \mathrm{ET}, \mathrm{SFT}, \mathrm{TT}$ & Ss5 & $03 / 10 / 00$ & C & 2 years & AP, SUT, TT \\
\hline Sf5 & $12 / 30 / 97$ & C & 6 months & $\mathrm{AP}, \mathrm{CO}, \mathrm{ET}, \mathrm{SFT}, \mathrm{TT}$ & Ss6 & 05/23/00 & C & 7 months & ET, SUT, TT \\
\hline Sf6 & $11 / 02 / 98$ & C & 2 years & $\mathrm{AP}, \mathrm{CO}, \mathrm{ET}, \mathrm{SFT}, \mathrm{TT}$ & Ss7 & $05 / 31 / 00$ & C & 87 years & ET, SUT, TT \\
\hline Sf7 & $09 / 16 / 98$ & $\mathrm{C}$ & 4 years & AP, ET, SUT, TT & Ss8 & $06 / 02 / 00$ & $\mathrm{C}$ & 2 years & ET, SUT, TT \\
\hline Sf8 & $01 / 21 / 99$ & C & 1 year & AP, CO, ET, SUT, TT & Ss9 & $01 / 25 / 01$ & cos & 2 years & SUT, TT \\
\hline Sf9 & $02 / 17 / 99$ & C & 70 years & AP, CO, ET, SUT, TT & Ss10 & 03/02/01 & $\mathrm{C}$ & 9 years & ET, SUT, TT \\
\hline Sf10 & 03/29/99 & C & 29 years & CO, ET, SUT, TT & Ss11 & 03/02/01 & C & 3 years & SUT, TT \\
\hline Sf11 & 09/30/99 & $\mathrm{C}$ & 11 months & AP, CO, ET, SUT, TT & Ss12 & 03/08/01 & $\mathrm{C}$ & 3 years & ET, SUT, TT \\
\hline Sf12A & $11 / 12 / 99$ & 1 & 50 years & AP, CO, ET, SUT, TT & Ss13 & 05/10/01 & $\mathrm{C}$ & 1 year & SUT, TT \\
\hline Sf12B & $11 / 12 / 99$ & I & 40 years & AP, CO, ET, SUT, TT & Ss14 & 06/29/01 & $\mathrm{C}$ & - & SUT, TT \\
\hline Sf12C & $11 / 16 / 99$ & I & 4 years & AP, CO, ET, SUT, TT & Ss 15 & $07 / 05 / 01$ & C & - & SUT, TT \\
\hline Sf12D & $11 / 30 / 99$ & I & 19 years & AP, CO, ET, SUT, TT & Ss16A & $02 / 28 / 02$ & C & 4 years & SUT, TT \\
\hline Sf13 & $02 / 14 / 00$ & C & 8 months & AP, CO, ET, SUT, TT & Ss16B & $02 / 28 / 02$ & $\mathrm{C}$ & 3 years & SUT, TT \\
\hline Sf14 & 05/02/00 & C & 5 years & AP, CO, ET, SUT, TT & Ss16C & 02/28/02 & $\mathrm{C}$ & 5 years & SUT, TT \\
\hline Sf15 & $05 / 15 / 00$ & C & 3 years & AP, CF, CO, ET, SUT, TT & Ss16D & 02/28/02 & C & 4 years & SUT, TT \\
\hline Sf16 & 06/05/00 & $\mathrm{C}$ & 4 years & AP, ET, SUT, TT & Ss16E & 02/28/02 & $\mathrm{C}$ & 5 years & SUT, TT \\
\hline Sf17 & $07 / 10 / 00$ & $\mathrm{C}$ & 6 months & AP, ET, SUT, TT & Ss $16 \mathrm{~F}$ & $02 / 28 / 02$ & $\mathrm{C}$ & - & SUT, TT \\
\hline Sf18 & $07 / 10 / 00$ & $\mathrm{C}$ & - & $\mathrm{AP}, \mathrm{ET}, \mathrm{TT}$ & Ss16G & 03/07/02 & $\mathrm{C}$ & 6 years & SUT, TT \\
\hline Sf19 & $08 / 15 / 00$ & C & 1.5 years & AP, CO, ET, SUT, TT & $\mathrm{Ss} 16 \mathrm{H}$ & $03 / 11 / 02$ & C & 42 years & SUT, TT \\
\hline Sf20 & $11 / 10 / 00$ & $\mathrm{C}$ & 5 years & $\mathrm{AP}, \mathrm{CO}, \mathrm{TT}$ & Ss16I & 03/26/02 & $\mathrm{C}$ & 6 years & SUT, TT \\
\hline Sf21 & $11 / 14 / 00$ & $\mathrm{C}$ & 50 years & AP, CO, SUT, TT & Ss 17 & $03 / 06 / 02$ & $\mathrm{C}$ & 5 years & SUT, TT \\
\hline Sf22 & $12 / 21 / 00$ & C & 5 years & AP, CO, ET, SUT, TT & Ss18 & 03/15/02 & $\mathrm{C}$ & - & SUT, TT \\
\hline Sf23 & 01/16/01 & C & 40 years & AP, CO, ET, SUT, TT & Ss19A & 04/18/02 & VIN & - & SUT, TT \\
\hline Sf24 & 01/22/01 & $\mathrm{C}$ & 10 months & $\mathrm{ET}, \mathrm{TT}$ & Ss19B & 04/18/02 & VIN & - & SUT, TT \\
\hline Sf25 & $06 / 18 / 01$ & MG & 49 years & SUT & Ss19C & $04 / 18 / 02$ & VIN & - & SUT, TT \\
\hline Sf26 & $12 / 27 / 01$ & $\mathrm{C}$ & 3 years & $\mathrm{AP}, \mathrm{CO}, \mathrm{TT}$ & Ss20 & $05 / 03 / 02$ & $\mathrm{C}$ & - & SUT, TT \\
\hline
\end{tabular}

SJBV = São João da Boa Vista; $C$ = Campinas; $J$ = Jundiaí; I = Itapira; MG = Mogi Guaçu; BP = Bragança Paulista; L = Limeira; COS = Cosmópolis; VIN = Vinhedo; $\mathrm{AP}$ = ampicillin; $\mathrm{CF}$ = cephalothin; $\mathrm{CO}$ = chloramphenicol; $\mathrm{ET}$ = streptomycin; SFT = trimethoprim-sulfamethoxazole; SUT = sulfamethoxazole; TT = tetracycline . 
Sf10, Sf15, Sf18, Sf20, Sf24, Sf25, and Sf26. Resistance to ampicillin (83.3\%), chloramphenicol $(70.0 \%)$, streptomycin $(86.7 \%)$, sulfamethoxazole $(80.0 \%)$, and tetracycline $(80.0 \%)$ was the most prevalent, whereas resistance to cephalothin $(3.3 \%)$ and sulfazotrim $(10.0 \%)$ was the least prevalent (Table 1 and Figure 1).

S. sonnei strains presented resistance to either $2(70.0 \%)$ or $3(30.0 \%)$ antimicrobial agents (Table 1). Resistance to sulfamethoxazole and tetracycline was present in 100.0 and $96.7 \%$ of the strains, respectively, and resistance to ampicillin (6.7\%) and streptomycin $(26.7 \%)$ was also detected in the strains studied (Table 1, Figure 1).

Plasmid analyses showed that S. flexneri and $S$. sonnei strains harbored high- and/or low-molecular weight plasmids (data not shown). On the basis of the existence and size of these plasmids, the strains of the two species were classified into 11 and 9 groups, respectively, but an association between strains belonging to a specific group and the place of isolation and antimicrobial drug resistance was not evident.

The recording of DNA fragments amplified by the three (ERIC-PCR, DRE-PCR, REPPCR) techniques (data not shown) permitted the classification of all $S$. flexneri strains into three main groups (A, B, and C; Figure 2). Group A contained 14 strains (Sf1A, Sf1B, Sf2-Sf8, Sf13-Sf15, Sf19, and Sf26). Among these, Sf1A and Sf1B were identical, with partial similarity with Sf5 (approximately 94\%); Sf2, Sf6, and Sf7 were identical, with partial similarity (approximately 97\%) with Sf8, Sf13-Sf15, and Sf26, which were identical to each another. Strains Sf3 and Sf4 were identical, with a similarity coefficient of approximately $91 \%$ with strains from groups containing strains Sf2 and Sf8. Group B contained 9 strains (Sf9, Sf10, Sf12A-Sf12D, Sf16Sf18). Strains Sf12A-Sf12D were identical and had a similarity coefficient of approximately $89 \%$ with strain Sf9. Strains Sf10 and Sf16-Sf18 were identical, with a similarity coefficient of approximately $80 \%$ with groups containing strains $\mathrm{Sf} 9$ and Sf12. Group C comprised 7 strains (Sf11 and Sf20-Sf25). Strains Sf21-Sf23 and SF25 were identical, with a similarity coefficient of approximately $81 \%$ with strains Sf11, SF20, and Sf24, which were identical. Groups A and B had a similarity coefficient of approximately $76 \%$ with one another and of $62 \%$ with group C.

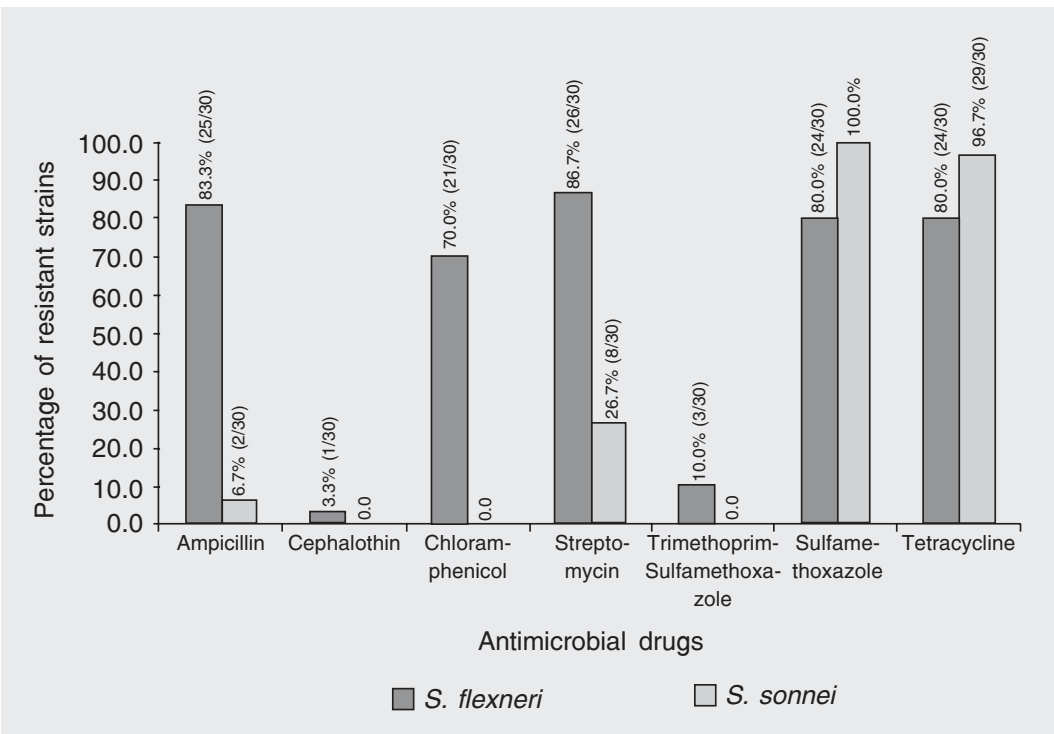

Figure 1. Percentage of Shigella spp strains resistant to different antimicrobial agents.

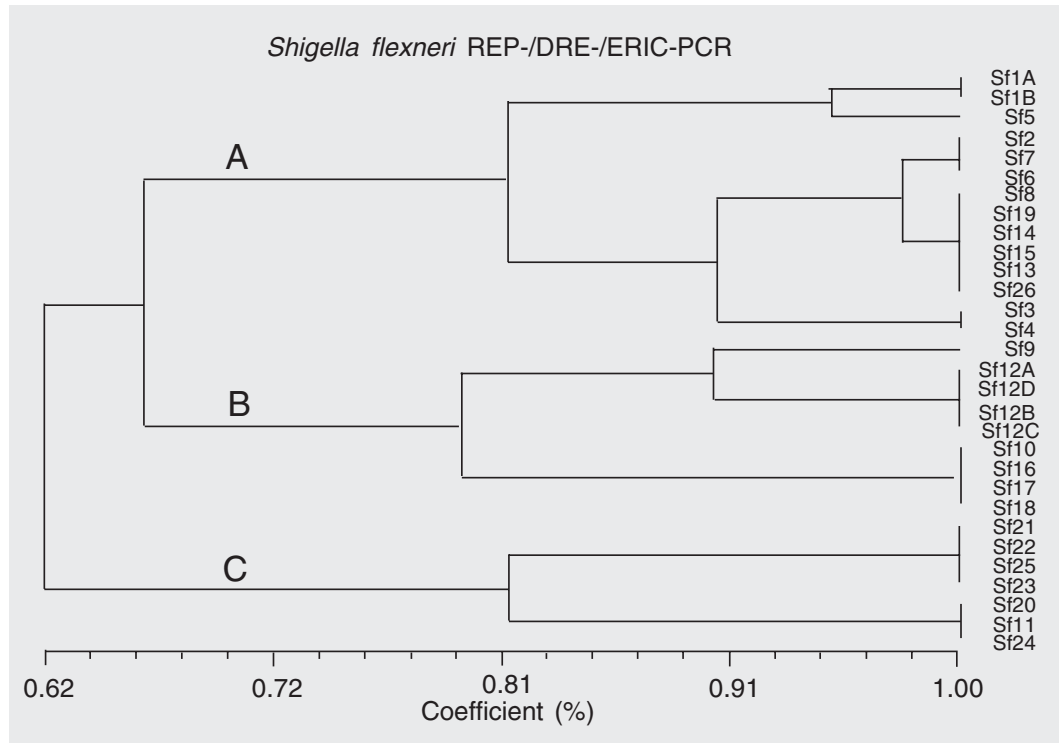

Figure 2. Similarity dendrogram generated for Shigella flexneri strains using the different (ERIC-PCR, REP-PCR, DRE-PCR) techniques. Group classification is indicated by the letters $A, B$ and $C$ on the dendrogram. See text. 
S. sonnei strains were also grouped into three main groups: A, B, and C (Figure 3). Group A contained 11 strains (Ss2, Ss4, Ss5, and Ss8-Ss15) and group B contained 14 strains (Ss1, Ss3, Ss6, Ss7, Ss16A-Ss16I, and Ss20). All strains numbered Ss16 were identical, with a similarity coefficient of approximately $85 \%$ with strains Ss6, Ss1, Ss3,

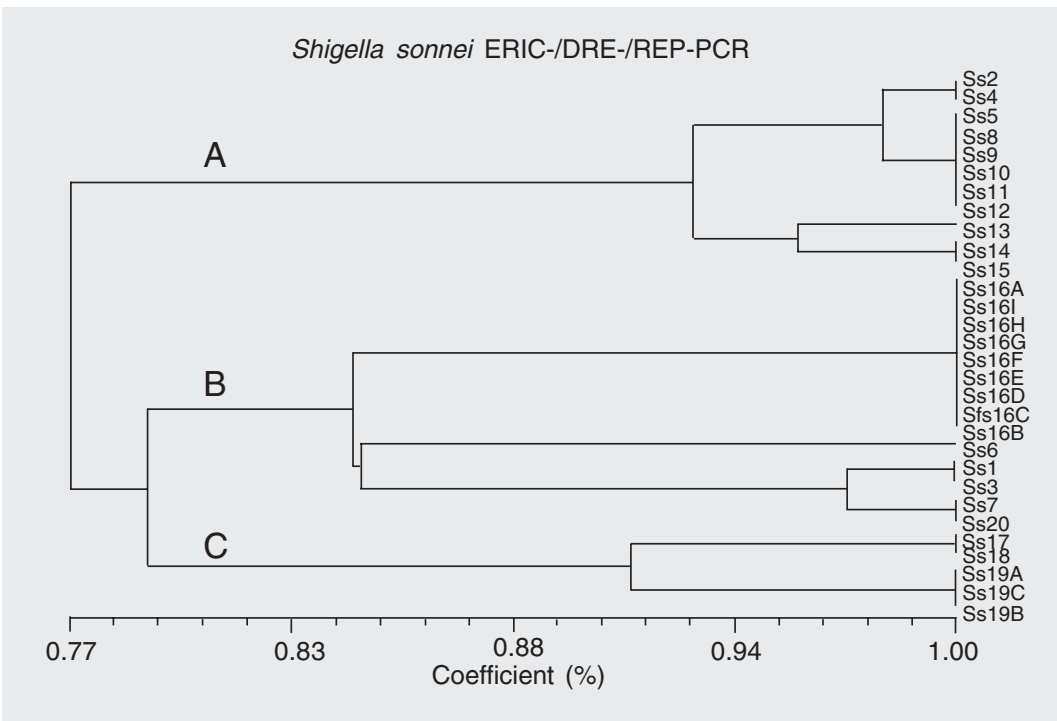

Figure 3. Similarity dendrogram generated for Shigella sonnei strains using the different (ERIC-PCR, REP-PCR, DRE-PCR) techniques. Group classification is indicated by the letters $A, B$ and $C$ on the dendrogram. See text.
Ss7, and Ss20. Strains Ss1 and Ss3 were identical, with a similarity coefficient of $96 \%$ with strains Ss7 and Ss20, which were identical. Group C comprised 5 strains (Ss17, Ss18, and Ss19A-Ss19C). Strains Ss17 and Ss18 were identical, with a similarity coefficient of approximately $92 \%$ with strains from group Ss19, which were identical. Groups B and $\mathrm{C}$ were more similar to each other $(79 \%)$ than to group A $(77 \%)$.

$S$. flexneri strains were isolated in 5 cities in the region of Campinas (Table 1, Figure 4): São João da Boa Vista (2), Jundiaí (1), Itapira (4), Campinas (22), and Mogi Guaçu (1). The number of strains is given between parentheses. Strains isolated in São João da Boa Vista were identical and were not detected in any other city. Strains isolated in Itapira were also identical and unique. Strain 3, isolated in Jundiaí (1990), was identical to strain 4, which was later (1997) isolated in Campinas. The 22 strains isolated in the city of Campinas could be sub-classified into eight patterns (or types), within the three groups observed (A, B, C) according to the amplified DNA fragments generated by PCR (Figure 2). Of these eight patterns, five in-
Figure 4. Time of isolation (per year) of the 30 Shigella flexneri strains isolated from patients in the different cities examined in the present study. Strains encircled by the same symbols belong to the same PCR type. Note that the time scale (years) is not linear.

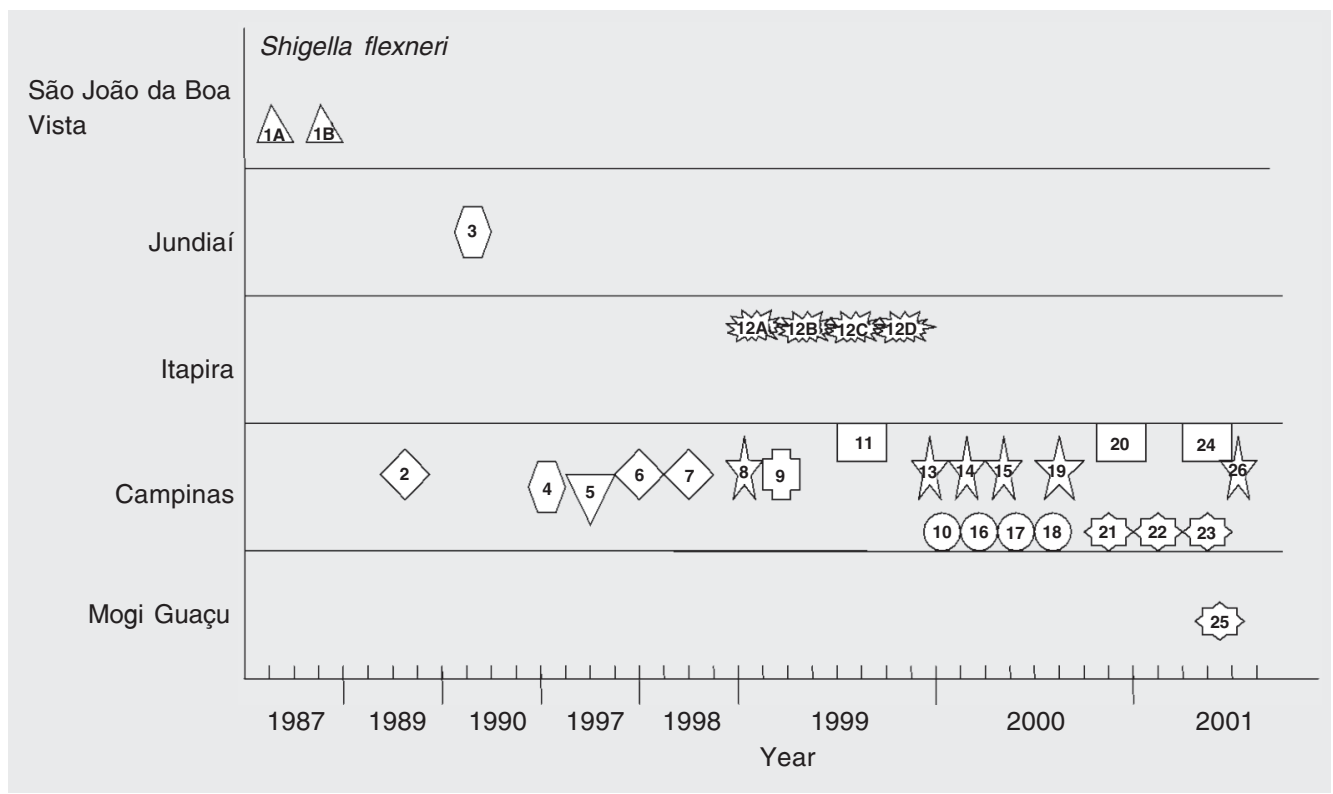


cluded most of the strains. Just one pattern was found for each one of strains 4, 5, and 9 . Strain 25, which was isolated in Mogi Guaçu $(06 / 18 / 01)$, was identical to strains 21,22 , and 23, which had been earlier isolated in Campinas (Figure 4).

A similar picture was obtained for $S$. sonnei, which was isolated in 6 cities in the region of Campinas. Most of the strains (23) were isolated in Campinas (Table 1, Figure 5). In Cosmópolis, only 1 strain (9) was isolated, exhibiting a pattern identical to that observed for strains 5 and 8 , and 10,11, and 12, isolated in Campinas in 2000 and 2001, respectively. Strain 1, which was isolated in Mogi Guaçu (1997), displayed a pattern identical to that of strain 3, isolated in Limeira (1998). Strain 2 isolated in Bragança Paulista (1998), also displayed a pattern identical to that of strain 4, later (1999) found in Campinas. Strains 19A, 19B, and 19C, isolated in Vinhedo, were identical to one another, but were different from the strains isolated in the other cities. The 22 strains obtained in Campinas could be classified into seven patterns respectively containing 9 strains $(16 \mathrm{~A}, 16 \mathrm{~B}, 16 \mathrm{C}, 16 \mathrm{D}, 16 \mathrm{E}, 16 \mathrm{~F}$, $16 \mathrm{G}, 16 \mathrm{H}$, and 16I), 5 strains $(5,8,10,11$, and 12), 3 strains (13, 14, and 15), 2 strains (7 and 20), 2 strains (17 and 18), and one strain each, namely 4 and 6 .

\section{Discussion}

Approximately 1.2 million people live in the city of Campinas, a major industrialized, technological, and educational center in the State of São Paulo, Southeast Brazil. Many other smaller cities are located in the region of Campinas and, although Campinas and these cities are considered to be developed cities with good living standards, a few slums have arisen because of migration from other Brazilian regions, a phenomenon that has worsened over the last decade. Also, many people from other cities commute every day for professional, educational, and leisure purposes. Taken together, these factors should facilitate the spread of infectious diseases, which would be very difficult to detect, eradicate, or control. Therefore, we decided to study all Shigella spp isolates ob-

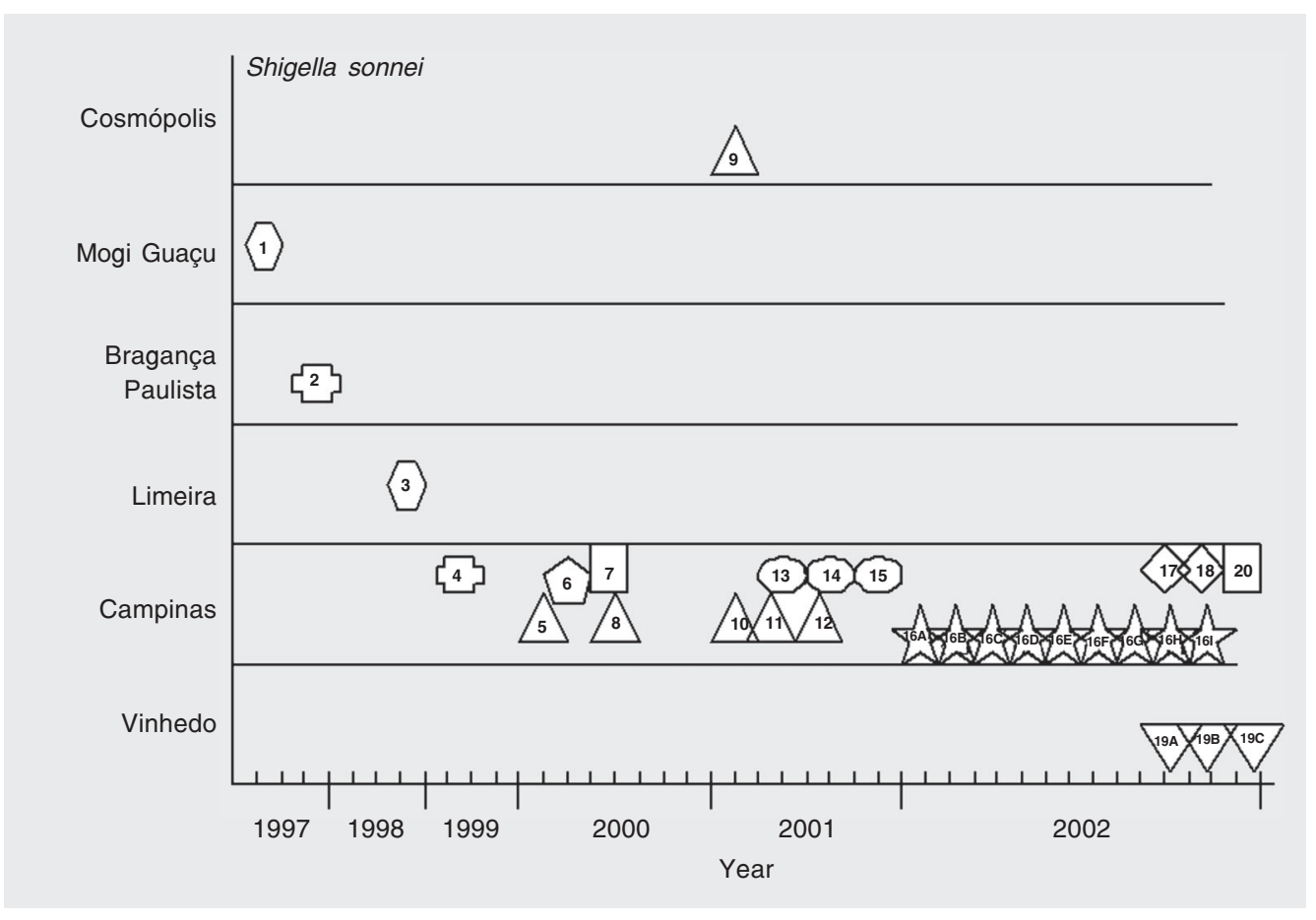

Figure 5. Isolation time (per year) of the 30 Shigella sonnei strains isolated from patients in the different cities examined in this study. Strains encircled by the same symbol belong to the same PCR type. Note that the time scale (years) is not linear. 
tained from different cases that occurred in the region of Campinas from 1987 to 2002, and which belong to the collection of the Adolfo Lutz Institute (the infectious disease reference Institute in the State of São Paulo). The present study has attempted to determine the genomic profile of these isolates and trace the possible origin of the cases. Since most molecular techniques presently available do not demonstrate a real difference between isolates in a definitive manner, we decided to use a combination of three separate but similar PCR techniques (ERIC-PCR, REP-PCR, DRE-PCR). Also, we associated these data with antibiotic resistance and plasmid profiles to help identify isolates and rule out a possible, but not real, positive identity. We also compared these strains with others previously isolated in Brazil.

In previous studies conducted in the Southeast region of Brazil (30-37), it was clearly demonstrated that Shigella infections are an important cause of morbidity and mortality. Fagundes-Neto and de Andrade (32) and Medeiros et al. (35) demonstrated that age can be a risk factor for Shigella infections, with most of the cases occurring among children under 6 and 11 months of age, respectively. In the present study, most of the strains of both S. flexneri and S. sonnei were isolated from patients under 6 years of age, indicating that age could be a risk factor. The isolation data for each strain (Table 1) allowed us to observe a possible seasonal bacterial distribution. This characteristic is extremely common in endemic areas (38) since most bacterial strains (70\%) were isolated during the warmest months of the year (January, February, March, April, October, November, and December) in Brazil. These data suggest a relationship between environmental conditions and pathogen dissemination.

Also in Brazil, Lima et al. (22) observed that almost $50 \%$ of the $S$. flexneri strains were resistant to ampicillin or trimethoprim- sulfamethoxazole, or both. Over $64 \%$ were resistant to streptomycin, chloramphenicol, and tetracycline, with $82 \%$ of all the strains being resistant to four or more of the antimicrobial agents tested. In a subsequent investigation, Lima et al. (23) studied the molecular epidemiology of the $S$. flexneri strains and concluded that they displayed only three plasmid profile patterns, and the strains were allocated to six pattern groups as determined by PFGE.

In a more recent paper describing the Brazilian Surveillance Program that used Shigella spp strains isolated by several centers, Oplustil et al. (39) observed that $80 \%$ of the strains exhibited a high level of resistance to trimethoprim-sulfamethoxazole. Resistance to ampicillin (33.3\%) and chloramphenicol (10.9\%) was also found among strains isolated from outpatients. None of the strains were resistant to ceftriaxone.

The pattern of resistance of the strains studied here resembles that reported by Lima et al. (22), but in our case the strains were also resistant to other antimicrobial agents such as chloramphenicol (70\%), streptomycin $(86.7 \%)$, and tetracycline $(80 \%)$, indicating that the chromosomal genes encoding ampicillin, chloramphenicol, streptomycin, and tetracycline resistance described by Casalino et al. (40) in Somalian strains could also have been selected in the region of Campinas. In addition, since most of the $S$. sonnei strains were resistant mainly to sulfamethoxazole and tetracycline, this may indicate that strains harboring specific gene loci were selected.

The determination of the plasmid profiles of all of these strains did not permit us to characterize the strains in a specific manner, although some plasmid patterns could be observed. Since plasmids are genetically mobile elements with a possible horizontal transfer capacity, it would not be surprising to find different plasmid patterns even among chromosomally identical strains. This would cast doubts on our results if we used them for 
characterization purposes, as was done by Lima et al. (23). Moreover, since the strains studied were isolated from cases of human infection, the pINV plasmid(s) would be expected to be present in all of the strains studied, tending to homogenize the results. Since plasmid profiling alone is not sufficient to characterize strains as identical or not, we decided to rely only on the results obtained by the PCR-based techniques.

Figures 2 and 3 show the genotypic profile as determined by combined analysis with the three PCR techniques used in the present study, and the isolation time of each strain in each city, for S. flexneri and S. sonnei, respectively. These data clearly demonstrate that there was some transmission of strains between cities, as was the case for strains 3 and 4 , and 23 and 25 of $S$. flexneri, transmitted between Jundiaí and Campinas, and between Campinas and Mogi Guaçu, respectively. Transmission between cities was also observed in the case of $S$. sonnei strains 1 (Mogi Guaçu) and 3 (Limeira), 2 (Bragança Paulista) and 4 (Campinas), strain 9 (Cosmópolis) and others isolated in Campinas (strains 5, 8, 10, 11, and 12).

Given the possibility that shigellosis manifests in an endemic manner (38), with cases occurring sporadically mainly in the warmest months of the year, and because most of the cases studied here were caused by very similar or identical strains, we may infer that these strains could survive in the environment either in contaminated water and food or in carriers such as humans and other animals. This hypothesis requires further study to confirm a role for environmental sources of infection.

We can conclude from the data discussed above that transmission of infectious Shigella spp strains occurred among individuals and between cities, with some of the strains being responsible for most of the cases. This evidence requires well-designed interventional strategies to control transmission of infectious diseases, in this case multiple antimicrobial-resistant Shigella strains. This control is more complex when the cases occur in highly populated areas, since there are many other risk-associated factors such as disadvantaged populations without a good standard of public health (treated water supplies, treated sewage, ingestion of inappropriate food) and the added risk factors of a high level of commuting and the presence of infected hosts that could serve as reservoirs of the pathogen.

\section{References}

1. Murray PR, Rosenthal KS, Kobayashi GS, Pfaller MA. Medical Microbiology. 3rd edn. St. Louis: Mosby-Year Book; 1998.

2. Jawetz E, Melnick JL, Adelber EA. Microbiologia Médica. Rio de Janeiro: Guanabara Koogan; 2000.

3. Sansonetti PJ. Rupture, invasion and inflammatory destruction of the intestinal barrier by Shigella, making sense of prokaryote-eukaryote cross-talks. FEMS Microbiol Rev 2001; 25: 3-14.

4. Thong KL, Hoe SL, Puthucheary SD, Yasin RM. Detection of virulence genes in Malaysian Shigella species by multiplex PCR assay. BMC Infect Dis 2005; 5: 8.

5. Parsot C. Shigella spp. and enteroinvasive Escherichia coli pathogenicity factors. FEMS Microbiol Lett 2005; 252: 11-18.

6. Kopecko DJ, Holcombe J, Formal SB. Molecular characterization of plasmids from virulent and spontaneously occurring avirulent colonial variants of Shigella flexneri. Infect Immun 1979; 24: 580-582.

7. Hale TL. Genetic basis of virulence in Shigella species. Microbiol Rev 1991; 55: 206-224.
8. Rolland K, Lambert-Zechovsky N, Picard B, Denamur E. Shigella and enteroinvasive Escherichia coli strains are derived from distinct ancestral strains of E. coli. Microbiology 1998; 144 (Pt 9): 26672672.

9. Coimbra RS, Grimont F, Grimont PA. Identification of Shigella serotypes by restriction of amplified O-antigen gene cluster. Res Microbiol 1999; 150: 543-553.

10. Joklik WK, Willet HP, Amos DB, Wilfert CM. Microbiología. Zinsser (Editor), Buenos Aires: Editora Médica Panamericana; 1994.

11. Shears P. Shigella infections. Ann Trop Med Parasitol 1996; 90: 105-114.

12. Ochman H, Whittam TS, Caugant DA, Selander RK. Enzyme polymorphism and genetic population structure in Escherichia coli and Shigella. J Gen Microbiol 1983; 129: 2715-2726.

13. Navia MM, Capitano L, Ruiz J, Vargas M, Urassa H, Schellemberg $D$, et al. Typing and characterization of mechanisms of resistance of Shigella spp. isolated from feces of children under 5 years of age 
from Ifakara, Tanzania. J Clin Microbiol 1999; 37: 3113-3117.

14. Surdeanu M, Ciudin L, Pencu E, Straut M. Comparative study of three different DNA fingerprint techniques for molecular typing of Shigella flexneri strains isolated in Romania. Eur J Epidemiol 2003; 18: 703-710.

15. Brenner DJ, Fanning GR, Miklos GV, Steigerwalt AG. Polynucleotide sequence relatedness among Shigella species. Int J Syst Bacteriol 1973; 23: 1-7.

16. Brenner DJ, Fanning GR, Skerman FJ, Falkow S. Polynucleotide sequence divergence among strains of Escherichia coli and closely related organisms. J Bacteriol 1972; 109: 953-965.

17. Brenner DJ, Steigerwalt AG, Wathen HG, Gross RJ, Rowe B. Confirmation of aerogenic strains of Shigella boydii 13 and further study of Shigella serotypes by DNA relatedness. J Clin Microbiol 1982; 16 : $432-436$.

18. Pupo GM, Karaolis DK, Lan R, Reeves PR. Evolutionary relationships among pathogenic and nonpathogenic Escherichia coli strains inferred from multilocus enzyme electrophoresis and mdh sequence studies. Infect Immun 1997; 65: 2685-2692.

19. Pupo GM, Lan R, Reeves PR. Multiple independent origins of Shigella clones of Escherichia coli and convergent evolution of many of their characteristics. Proc Natl Acad Sci U S A 2000; 97: 1056710572.

20. Lee TM, Chang CY, Chang LL, Chen WM, Wang TK, Chang SF. One predominant type of genetically closely related Shigella sonnei prevalent in four sequential outbreaks in school children. Diagn Microbiol Infect Dis 2003; 45: 173-181.

21. Liu PY, Lau YJ, Hu BS, Shyr JM, Shi ZY, Tsai WS, et al. Analysis of clonal relationships among isolates of Shigella sonnei by different molecular typing methods. J Clin Microbiol 1995; 33: 1779-1783.

22. Lima AA, Lima NL, Pinho MC, Barros Junior EA, Teixeira MJ, Martins $\mathrm{MC}$, et al. High frequency of strains multiply resistant to ampicillin, trimethoprim-sulfamethoxazole, streptomycin, chloramphenicol, and tetracycline isolated from patients with shigellosis in northeastern Brazil during the period 1988 to 1993. Antimicrob Agents Chemother 1995; 39: 256-259.

23. Lima AA, Sidrim JJ, Lima NL, Titlow W, Evans ME, Greenberg RN. Molecular epidemiology of multiply antibiotic-resistant Shigella flexneri in Fortaleza, Brazil. J Clin Microbiol 1997; 35: 1061-1065.

24. Lan R, Alles MC, Donohoe K, Martinez MB, Reeves PR. Molecular evolutionary relationships of enteroinvasive Escherichia coli and Shigella spp. Infect Immun 2004; 72: 5080-5088.

25. Versalovic J, Koeuth T, Lupski JR. Distribution of repetitive DNA sequences in eubacteria and application to fingerprinting of bacterial genomes. Nucleic Acids Res 1991; 19: 6823-6831.

26. Friedman CR, Stoeckle MY, Johnson WD Jr, Riley LW. Double- repetitive-element PCR method for subtyping Mycobacterium tuberculosis clinical isolates. J Clin Microbiol 1995; 33: 1383-1384.

27. Ausubel FM, Brent R, Kingston RE, Struhl K, Moore DD, Smith JÁ, et al. Current protocols in molecular biology. Brooklyn: Greene Publishing Associates; 1988.

28. Sambrook J, Fritsch EF, Maniatis T. Molecular cloning: a laboratory manual. 2nd edn. New York: Cold Spring Harbor Laboratory Press; 1989.

29. Yeh FC, Yang RC, Boyle T. Popgene, version 1.31. Microsoft Windows-based freeware for population genetic analysis. http://www. ualberta.ca/ fyeh/.

30. Almeida MT, Silva RM, Donaire LM, Moreira LE, Martinez MB. Enteropathogens associated with acute diarrheal disease in children. J Pediatr 1998; 74: 291-298.

31. de Andrade JA, de Oliveira JO, Fagundes NU. Lethality in hospitalized infants with acute diarrhea: risk factors associated with death. Rev Assoc Med Bras 1999; 45: 121-127.

32. Fagundes-Neto $U$, de Andrade JA. Acute diarrhea and malnutrition: lethality risk in hospitalized infants. J Am Coll Nutr 1999; 18: 303308.

33. Fernandes MR, Trabulsi LR. Infectious resistance in pathogenic enteric organisms isolated in São Paulo, Brasil (Preliminary report). Rev Inst Med Trop São Paulo 1968; 10: 52-53.

34. Gomes TA, Rassi V, MacDonald KL, Ramos SR, Trabulsi LR, Vieira MA, et al. Enteropathogens associated with acute diarrheal disease in urban infants in São Paulo, Brazil. J Infect Dis 1991; 164: 331337.

35. Medeiros LC, Hillers VN, Kendall PA, Mason A. Food safety education: what should we be teaching to consumers? J Nutr Educ 2001; 33: 108-113.

36. Piechaud D, Szturm-Rubinsten S, Pessoa G. Diversity of resistance types among Shigella in São Paulo (Brasil) (author's transl). Ann Microbiol 1974; 125: 581-584.

37. Zuliani ME, Trabulsi LR. In vitro sensitivity of 166 Shigella strains isolated in São Paulo, Brazil, to sulphadiazine and five antibiotics. Rev Inst Med Trop São Paulo 1968; 10: 70-77.

38. Sears CL, Kaper JB. Enteric bacterial toxins: mechanisms of action and linkage to intestinal secretion. Microbiol Rev 1996; 60: 167-215.

39. Oplustil CP, Nunes R, Mendes C. Multicenter evaluation of resistance patterns of Klebsiella pneumoniae, Escherichia coli, Salmonella spp and Shigella spp isolated from clinical specimens in Brazil: RESISTNET Surveillance Program. Braz J Infect Dis 2001; 5: 8-12.

40. Casalino M, Nicoletti M, Salvia A, Colonna B, Pazzani C, Calconi A, et al. Characterization of endemic Shigella flexneri strains in Somalia: antimicrobial resistance, plasmid profiles, and serotype correlation. J Clin Microbiol 1994; 32: 1179-1183. 